\title{
Acessibilidade Linguística de Surdos no Ensino Superior: Reflexófes Sobre o Curso de Letras Libras/Língua Portuguesa da Universidade Federal do Rio Grande do Norte ${ }^{1}$
}

LINGUISTICACCESSIBILITY FOR DEAF PEOPLE IN HIGHER EDUCATION: REFLECTIONS about the Brazilian Sign LANGUage/Portuguese Language UNDERGRAdUATE CoURSE of THE FEDERAL UNIVERSITY OF RIO GRANDE DO NORTE

\author{
Gisele Oliveira da Silva PAIVA² \\ Francisco Ricardo Lins Vieira de MELO ${ }^{3}$
}

\begin{abstract}
RESUMO: Este trabalho teve como objetivo conhecer quais açoes concernentes à acessibilidade linguística da Pessoa Surda foram implementadas pelo Curso de Letras Libras/Língua Portuguesa (CLLLP) da Universidade Federal do Rio Grande do Norte (UFRN). A construção deste estudo ocorreu com base nos dados elaborados durante a pesquisa de Mestrado intitulada Estudantes Surdos no Ensino Superior: reflexóes sobre a inclusão no curso de Letras-Libras/Língua Portuguesa da UFRN. Mais especificamente, empenhamos esforços em lançar um olhar para a categoria "acessibilidade linguística" que foi construída a partir de uma entrevista em Libras com sete estudantes surdos do curso. Para tanto, entremeamos as açôes voltadas à acessibilidade linguística dos surdos envolvendo o curso de LLLP com os discursos desses sujeitos. Desse modo, orientamos nossas discussóes teóricas considerando as raízes históricas da Educação de Surdos, dos Estudos Surdos, da Políticas Linguísticas e dos Estudos Culturais. Finalmente, observamos a importância de considerar as devolutivas dos surdos acerca das açóes promovidas pelo CLLLP para oportunizar a efetivaçáo do direito linguístico da Pessoa Surda em todos os espaços da universidade. E, ainda, da necessidade de um movimento de reflexão constante para o engendramento de estratégias institucionais que contribuam para o enfrentamento dos desafios de implementaçấo da acessibilidade linguística e, por conseguinte, assegurem o acesso e a permanência com qualidade do Surdo no Ensino Superior.
\end{abstract}

PALAVRAS-CHAVE: Acessibilidade. Surdo. Ensino Superior.

\begin{abstract}
This work aimed to know which actions concerning the linguistic accessibility for deaf people have been implemented by the Brazilian Sign Language/Portuguese Language Undergraduate Course (Curso de Letras Libras/ Lingua Portuguesa - CLLLP) of the Federal University of Rio Grande do Norte (Universidade Federal do Rio Grande do Norte - UFRN). The construction of this study was based on data elaborated during the Master's research entitled 'Deaf Students in Higher Education: reflections on the inclusion in the Brazilian Sign Language/Portuguese Language Undergraduate Course at UFRN'. More specifically, we endeavor to glance at the "linguistic accessibility" category that was built from an interview in Brazilian Sign Language with seven deaf students from the course. To this end, we interweave actions aimed at the linguistic accessibility of the deaf involving the CLLLP course with the speeches of these subjects. In this way, we guide our theoretical discussions considering the historical roots of the Deaf Education, Deaf Studies, Linguistic Policies and Cultural Studies. Finally, we observed the importance of considering the feedback of the deaf about the actions promoted by CLLLP to provide opportunities for the deaf person's linguistic rights to be implemented in all spaces of the university. And, still, the need for a constant reflection movement to generate institutional strategies that contribute to face the challenges of implementing linguistic accessibility and, therefore, ensure the access and permanence with quality of the Deaf in Higher Education.
\end{abstract}

KEYWORDS: Accessibility. Deaf. Higher Education.

\footnotetext{
${ }^{1}$ https://doi.org/10.1590/1980-54702021v27e0154

${ }^{2}$ Docente do curso de Letras Libras/Língua Portuguesa. Universidade Federal do Rio Grande do Norte (UFRN). Mestre em Educação pelo Programa de Pós-Graduação em Educação da UFRN. Natal/Rio Grande do Norte/Brasil. E-mail: giseleoliveira.psi@ gmail.com. ORCID: https://orcid.org/0000-0001-9006-2552

${ }^{3}$ Professor associado do Departamento de Fisioterapia e do Programa de Pós-Graduação em Educação da UFRN. Natal/Rio Grande do Norte, Brasil. E-mail: ricardolins67@gmail.com. ORCID: https://orcid.org/0000-0001-5902-9615
} 


\section{INTRODUÇÁo}

O discurso construído sobre o surdo apoiou-se, historicamente, em torno de argumentos médicos, filosóficos, jurídicos e religiosos. Do período da Antiguidade à Idade Média, por exemplo, tais construçóes estavam vinculadas às histórias sobrenaturais e, inclusive, eram consideradas "imbecis" (Lacerda, 1998). Somente a partir do século XVI que foram considerados educáveis, porém os processos de ensino e de aprendizagem desses sujeitos não contemplava os aspectos próprios das esferas educacionais ${ }^{4}$ (Lacerda \& Lodi, 2009). Na realidade, as discussóes sobre a educação de surdos estavam ligadas à questão de qual língua eles deveriam ser expostos; assim, eram localizados em meio a pedagogias que envolviam o desenvolvimento da língua oral e/ou a "permissão"s para o uso da língua de sinais.

Durante o período de 1880 a 1960, o discurso dominante ouvintista esteve voltado, prioritariamente, à correçáo do corpo disforme do surdo com o intuito de atingir o padráo do que era considerado normal seguindo o modelo ouvinte (Lodi, 2004). Desse modo, as singularidades concernentes à pessoa surda constituíam alteraçôes patológicas que deveriam ser minimizadas por meio de práticas clínico-pedagógicas para o desenvolvimento da oralidade (treino articulatório) e o reestabelecimento da audição pelo uso de aparelhos. Entretanto, na década de 1980, surgem contornos iniciais de um movimento mundial em prol da necessidade de uma política bilíngue que considera a importância de o surdo desenvolver a língua de sinais como primeira língua e a língua oral na modalidade escrita, como segunda língua (Lodi, 2004).

As articulações políticas em benefício do reconhecimento político-cultural das línguas de sinais contribuíram para o desdobramento de açóes/orientaçóes que contemplassem a acessibilidade linguística para surdos. Todavia, diante desse conjunto de políticas, que reconhecem e/ou oficializam legalmente a língua de sinais em contextos bilíngues, tornam-se necessárias algumas ponderaçôes acerca da crença de que tais princípios se resumem apenas às leis, conforme veremos a seguir.

Quando há essa crença disseminada pelas diferentes entidades, sejam elas governamentais ou não, o risco de cair em uma emboscada é certeiro. Essa armadilha se alimenta da ideia equivocada de que bastariam as leis para institucionalizar a conquista de direitos, quando na verdade a lei proporciona um grau de letargia pouco explorado e debatido no meio acadêmico. Com isso, náo estamos desmerecendo o importante papel desempenhado pelas leis, apenas alertamos para as implicaçóes oriundas desse reconhecimento, que precisa constantemente ser revisado e reconfigurado conforme as demandas das comunidades linguísticas. (Santos \& Francisco, 2018, p. 2946)

Assim, advogamos a imprescindibilidade de considerar a compreensão da acessibilidade linguística entremeada pelos documentos legais e pela visibilidade das alternativas para as problemáticas sociais manifestadas pelo movimento surdo. Isso posto, neste trabalho, iremos operar com os termos "direito linguístico" e "acessibilidade linguística" atravessados pelo mesmo sentido valorativo - como políticas linguísticas voltadas não apenas à língua, mas à contingência, à historicidade, à subjetividade e às histórias locais que constituem a comunidade surda.

\footnotetext{
${ }^{4}$ Os métodos de ensino, as práticas realizadas, assim como os conteúdos ensinados, foram submetidos ao fator linguístico e abordados com o objetivo de descrever e sustentar a defesa pelo desenvolvimento da língua oral ou de sinais (Lodi, 2004, p. 14).

${ }^{5} \mathrm{O}$ termo permissão foi utilizado devido à educação de surdos sempre ter sido determinada por ouvintes que se auto atribuíram poder para a tomada dessa decisăo (Lodi, 2004, p. 14).
} 
Após tais esclarecimentos, adentramos a importância das políticas linguísticas que fortaleceram os direitos sociais, culturais, educacionais e linguísticos dos surdos. Podemos destacar a Lei $\mathrm{n}^{\circ}$ 10.098, de 19 de dezembro de 2000 (Lei de Acessibilidade), a Lei n 10.436, de 24 de abril de 2002 (Lei de Libras) e o Decreto n 5.626, de 22 de dezembro de 2005.

A primeira legislação trata sobre normas e critérios fundamentais para a viabilização da acessibilidade das pessoas com deficiência ou mobilidade reduzida. No tocante às pessoas surdas, salientamos o artigo $3^{\circ}$, inciso IX, que versa a respeito da comunicação em que "abrange, entre outras opções, as línguas, inclusive a Língua Brasileira de Sinais (Libras), a visualização de textos, o Braille, o sistema de sinalização ou de comunicação tátil, os caracteres ampliados" (Lei $\left.\mathrm{n}^{\circ} 10.098,2000\right)$. Vale sublinhar que esse item foi incluído pela Lei no 13.146 , de 6 de julho de 2015 - Lei Brasileira de Inclusão da Pessoa com Deficiência - Estatuto da Pessoa com Deficiência.

A segunda, Lei de Libras, reconhece a Língua Brasileira de Sinais como sistema linguístico de transmissão de ideias e fatos, ou seja, modo legal de comunicação e expressão inerentes da comunidade surda (Lei $\left.n^{\circ} 10.436,2002\right)$. E, ainda, garante a inclusão da disciplina de Libras no Ensino Superior, sendo de forma obrigatória nos cursos de Educação Especial, de Fonoaudiologia e de Magistério. A terceira legislação, referente ao Decreto nº 5.626/2005, que regulamentou a Lei de Libras e o artigo 18 da Lei de Acessibilidade, prevê questóes acerca da formação de profissionais que contribuam para o atendimento e a inclusão dos sujeitos surdos (docentes e instrutores para o ensino de Libras, tradutores e intérpretes de Libras), o acesso das pessoas surdas à educação e aos serviços de saúde e, finalmente, o apoio ao uso e a difusão da Libras pelo poder público e privado. Tal contexto, resultante de políticas linguísticas e de inclusão, possibilitaram que os surdos adentrassem outros espaços, de forma a oportunizar que a comunidade surda experienciasse importantes mudanças.

As transformações que atingiram os surdos são muitas. Elas perpassam os campos da política, da cultura dominante e se apropriam de novas questóes que visam à construçáo do povo surdo. Nossas independências dos espaços ouvintes dependem da conquista de alguns espaços onde é possível a interaçáo entre surdos que permita a construção de nossas narrativas; nossas representaçôes e identidades. (Perlin \& Reis, 2012, p. 41)

As referidas transformaçóes ampliaram a percepção das diversas possibilidades que os surdos podem alcançar, incluindo a entrada no Ensino Superior. Sobre a admissão desses sujeitos na academia, Quadros (2014) realizou um cotejamento de dados referentes ao ano de 2002 (304 alunos) e ao ano de 2005 (2.428 alunos), comprovando um aumento acelerado no quantitativo de universitários surdos. É interessante notar que o curso de Licenciatura em Letras Libras surgiu no Brasil em 2005, atendendo ao Decreto $n^{\circ} 5.626 / 2005$ de criação de cursos de formação de professores de Libras, tendo sua primeira turma composta por cerca de 90\% de alunos surdos (Quadros, 2014).

Corroborando esse cenário, as universidades, assim como as demais instituições de ensino, devem, portanto, implementar medidas que assegurem o acesso à comunicação, à informação e à educação (Decreto n ${ }^{\circ}$ 5.626/2005). Esse movimento social, político e legal atuando em território hierarquizado e com fronteiras epistemológicas demarcadas - revela a necessidade de que as instituiçóes educacionais reconheçam a existência de um outro sujeito em contexto de diferença. Essa dinâmica proporciona o acolhimento do jeito surdo de ser, retiran- 
do os surdos da condição de sujeitos idênticos e $\operatorname{amorfos}^{6}$ (Han, 2018). Pode-se dizer que, no momento que se manifesta na educação de surdos a diferença cultural e valorativa pertencente à comunidade surda, dá-se a oportunidade do entendimento de que "o outro, em sua irrupção, é infinitamente outro" (Skliar, 2003, p. 148).

Dessa maneira, com base nos Estudos culturais e nos Estudos Surdos, cabe à comunidade surda usufruir do "banquete" totêmico ${ }^{7}$ de torna-se surdo, orgulhando-se da sua cultura e da língua de sinais (Perlin \& Reis, 2012). Nesse sentido, assumem o papel de protagonistas na luta por uma educação que contemple às suas especificidades para o acesso, a permanência e a formação de qualidade no Ensino Superior.

Compreendendo que o conhecimento se constitui e é constituído pela linguagem, percebemos a importância de discutirmos a questão do direito linguístico, que se apresenta como aspecto fundamental para a inclusão dos surdos no Ensino Superior. Sobre a imprescindibilidade da acessibilidade linguística, a Lei no $13.146 / 2015$, capítulo IV, inciso IV, defende que a educação bilíngue deva ser ofertada "em Libras como primeira língua e na modalidade escrita da língua portuguesa como segunda língua, em escolas e classes bilíngues e em escolas inclusivas”. A pessoa com deficiência, por conseguinte, tem direito à educaçáo por meio de sistemas educacionais inclusivos (em todos os níveis e aprendizado ao longo da vida) segundo suas peculiaridades, interesses e necessidades de aprendizagem.

Diante da ampliação da entrada dos surdos no Ensino Superior, propomos conhecer quais açôes concernentes à acessibilidade linguística da pessoa surda foram implementadas pelo Curso de Letras-Libras/Língua Portuguesa (CLLLP) da Universidade Federal do Rio Grande do Norte (UFRN). Dentre os argumentos que justificam a escolha de nosso objeto de pesquisa, podemos elencar três eixos principais: o primeiro refere-se à realidade do curso abarcar a maior quantidade de surdos da UFRN, figurando, dessa forma, como um local de livre circulação da língua de sinais. O segundo está voltado à existência de diretrizes da própria UFRN, que tratam sobre açóes que diretamente contemplam a inclusão das pessoas com deficiência na instituiçãa. Por fim, pretendemos contribuir com as construçóes contemporâneas que evocam conhecimentos de uma agenda de pesquisa que localize os sujeitos sociais no centro dos debates, levando em conta as histórias locais e as necessidades daqueles situados em terrenos periféricos.

$\mathrm{O}$ artigo está arranjado seguindo o planejamento, a saber: inicialmente, na introdução, realizamos as principais reflexôes teóricas que embasam nossa pesquisa assim como a justificativa. Em seguida, destacamos os procedimentos metodológicos e apresentamos a análise dos registros das questóes formuladas nas entrevistas com os sujeitos da pesquisa. Por fim, nossas discussóes finais apontam para a importância de levar em conta as devolutivas dos surdos sobre a acessibilidade linguística nos espaços da UFRN e de a instituição empreender um movimento de (re)pensar estratégias e açóes que garantam a efetivação do direito linguístico desses sujeitos.

\footnotetext{
6 "falta ao idêntico o contrário dialético que o limitaria e lhe daria forma: cresce transformando-se numa massa amorfa [...]. À falta de tensão dialética, o que surge é uma sobreposição indiferente, uma massa proliferante de indiscernível”. (Han, 2018, p. 10-11)

${ }^{7} \mathrm{O}$ totêmico como agenciador que faz com que os surdos se sintam de igual para igual. Um agenciador, por exemplo, a língua de sinais, os movimentos das mãos no ar, proporciona uma grande atração para a visão dos surdos vendo várias expressões faciais do encontro-encontro surdos totêmicos (Perlin \& Reis, 2012, p. 33).
} 


\section{Método}

O artigo apresenta a análise de um recorte do trabalho de Mestrado de Paiva (2017), intitulado Estudantes surdos no ensino superior: reflexóes sobre a inclusáo no curso de Letras Libras/ Lingua Portuguesa da UFRN. A pesquisa teve como objetivo conhecer e analisar a opiniáo de alunos surdos sobre o curso de Letras Libras da UFRN em relaçáo a sua formaçáo acadêmica. A coleta dos dados ocorreu por meio da realização de entrevistas semiestruturadas e em Libras com sete surdos, regularmente matriculados nas turmas de 2013.2 e 2014.2 do referido curso, e da análise de documentos institucionais (Plano de Desenvolvimento Institucional da UFRN (2010-2019) e o Projeto Pedagógico do Curso de LLLP (2013)). A partir da análise dos dados, foram construídas três categorias, a saber: acessibilidade no curso de LLLP, currículo e atuação dos docentes no curso.

\section{Resultados E Discussóes}

Dentre as categorias elaboradas no decorrer da pesquisa de Mestrado, conforme explicitado anteriormente, deter-nos-emos na questáo da acessibilidade linguística no curso de Letras-Libras/Língua Portuguesa da UFRN. Em verdade, ao entremearmos as açóes voltadas a oportunizar a viabilização dos direitos linguísticos dos surdos no Ensino Superior com os discursos desses sujeitos, torna-se possível apreendermos informaçóes a respeito das potencialidades do que tem sido proposto pelo curso de LLLP.

Desse modo, propomos conhecer quais açóes concernentes à acessibilidade linguística da pessoa surda foram implementadas pelo Curso de Letras-Libras/Língua Portuguesa (CLLLP) da Universidade Federal do Rio Grande do Norte (UFRN). Isso posto, na categoria acessibilidade linguística, trataremos dos seguintes tópicos: acesso ao curso de LLLP por meio de vestibular especial (Teste de Habilidades Específicas - THE e Redação), atuação dos Tradutores/Intérpretes de Libras no contexto do curso e atuação dos técnicos que atendem aos alunos do Letras-Libras/LP.

\subsection{ACESSO AO CURSO DE LLLP DA UFRN}

O ingresso no curso de LLLP da UFRN ocorre por meio de um vestibular especial realizado pelo Núcleo Permanente de Concursos (COMPERVE), diferentemente do processo ocorrido na maioria dos cursos da universidade, em que a entrada acontece via SISU ${ }^{8}$. Essa parceria entre a UFRN e a COMPERVE foi uma importante ação para implementar, desde a primeira edição, uma forma de acesso que considerasse a especificidade linguística do candidato surdo (Oliveira \& Silva, 2016).

A seleção é composta por duas etapas: a primeira refere-se a uma prova objetiva em Libras denominada de Teste de Habilidades Específicas (THE), e a segunda constitui-se de uma redação em Língua Portuguesa escrita. Sobre o THE, no aspecto relacionado à acessibilidade desse formato avaliativo, temos os seguintes relatos:

\footnotetext{
${ }^{8}$ SISU: O Sistema de Seleção Unificada (Sisu) é o sistema informatizado gerenciado pelo Ministério da Educação (MEC) no qual instituiçóes públicas de Ensino Superior oferecem vagas para candidatos participantes do Exame Nacional de Ensino Médio (Enem). Para mais informaçōes: http://sisu.mec.gov.br/
} 
O vestibular do Letras Libras é sim acessível. A prova é em Libras por meio de vídeo. Para o acesso também tem uma parte escrita. A prova sendo toda em português não nos ajuda, mas a prova sendo em Libras, é visual. Faz com que seja acessível e que os alunos entrem na UFRN. (Rubi $\left.{ }^{9}, 2016\right)$

Na verdade, o THE é importante, em outras provas há barreiras. Com o THE existe uma acessibilidade maior para os surdos e consequentemente sua aprovação. Faz parte da acessibilidade. (Pérola, 2016)

Os posicionamentos dos partícipes fortalecem a compreensão de que a acessibilidade para o surdo, de fato, está vinculada à expressão e à circulação da Libras, privilegiando que ele seja avaliado pelo conhecimento construído em primeira e segunda língua (Libras e Português). Outra questão interessante nesse processo seletivo acessível em Libras está na maior possibilidade de equiparação de oportunidades entre surdos e ouvintes para pleitearem a admissão no curso. Além de responder a uma demanda afincadamente advogada pela comunidade surda: o direito de participar dos processos seletivos por meio da língua de sinais (Lei n 13.146/2015, Art. 30).

Como resultado dessa articulação e abertura da instituição em realizar parte do processo seletivo em Língua de Sinais, tivemos a entrada de surdos em todas as edições (Tabela 1) até o fim da realização deste estudo (2013 a 2016), conforme os dados postos à disposição no site da COMPERVE ${ }^{10}$.

\section{Tabela 1}

Quantidade de vagas preenchidas por surdos em cada edição do vestibular do curso de Letras-Libras/ Lingua Portuguesa da UFRN

\begin{tabular}{cccc}
\hline Ano de ingresso & Vagas ofertadas & Vagas preenchidas & Vagas preenchidas por surdos \\
2013 & 40 & 40 & 13 \\
2014 & 40 & 40 & 3 \\
2015 & 40 & 40 & 11 \\
2016 & 40 & 40 & 9 \\
\hline
\end{tabular}

Nota. Dados com base em informaçóes disponibilizadas pela COMPERVE.

Outro ponto importante levantado pelos participantes da pesquisa diz respeito ao nível de fluência em Libras dos alunos ingressantes.

O ouvinte precisa chegar sabendo a Língua de Sinais para ele poder interagir com os colegas surdos. Se não sabe Libras, haverá uma barreira entre os alunos. É preciso esse conhecimento para poder acessar os conteúdos. Isso é principal. (Rubi, 2016)

\footnotetext{
${ }^{9}$ Os participantes entrevistados na pesquisa foram representados por nomes de pedras preciosas, preservando as suas identidades, a saber: Rubi, Pérola, Esmeralda, Musgravite, Safira, Berilo Vermelho e Aquamarine.

${ }^{10}$ Sítio oficial da COMPERVE: http://www.comperve.ufrn.br/
} 
O conhecimento da língua de sinais tornou-se pré-requisito, pois a Libras está posta como língua de instrução, sendo as aulas ministradas por docentes bilíngues ${ }^{11}$. Tal direcionamento encontra-se preconizado no Projeto Político Pedagógico do Curso de LLLP (UFRN, 2013), convocando-os à condição de sujeitos bilíngues desde antes da aprovação no vestibular.

A proposição de um processo avaliativo bilíngue também revela outras complexidades das contingências da pessoa surda. Podemos presumir, por exemplo, que tal configuração do vestibular especial poderia conceder ao candidato surdo maior probabilidade de sucesso do que o vestibulando ouvinte. Contudo, observamos que pensamentos como esses apresentam dissonâncias com a realidade educacional a que foram submetidos os surdos.

Quando fiz o vestibular para o Letras-Libras fiquei surpreso porque foram poucos surdos a serem aprovados. Fiquei me perguntando 'Como podem os surdos não terem passado numa prova em Libras?'. Isso não estava certo. As perguntas eram simples, eram apenas de interpretação. Apenas olhava o vídeo e entendia o que estava falando e já marcava. (Rubi, 2016)

Segundo Lacerda e Lodi (2009), propostas educacionais que desconsideram a língua de sinais acarretam "uma série de limitaçóes, levando-os ao final da escolarização fundamental (não alcançada por muitos) a não serem capazes de ler e escrever satisfatoriamente ou terem um domínio adequado dos conteúdos acadêmicos" (p. 11). Desse modo, mesmo que o processo seletivo oportunize a presença da Libras, as lacunas inerentes ao processo formativo dos surdos revelam marcas na compreensão do registro formal dessa língua, fazendo com que muitos surdos não avancem em termos conceituais sobre a própria língua.

Desde cedo, a criança ouvinte tem a oportunidade de conviver com a língua utilizada por sua família. O interlocutor adulto colabora para que a linguagem da criança flua, oportunizando atitudes discursivas que favorecem o desenvolvimento e a apropriação de aspectos socioculturais e linguísticos importantes. As crianças surdas, em geral, não têm possibilidades para esse/a desenvolvimento/apropriação, já que na maioria das vezes não tem acesso à língua utilizada por seus pais (ouvintes). Tais crianças permanecem no meio familiar aprendendo coisas do mundo e da linguagem de forma fragmentada, dada a impossibilidade de acesso à língua a qual estáo sendo expostas. (Lacerda \& Lodi, 2009, p. 14)

Corroborando com esse pensamento, Silva (2012) alerta que se deve atentar para a questão da não aquisição da linguagem completa pelo surdo, visto que os surdos aprendem a sinalizar com seus pares surdos nas associaçôes de surdos e/ou escolas, mas não há um ensino específico sobre as regras e formas de uso da Língua de Sinais, não há uma introdução ao que é a atividade de ler em sinais, por exemplo. Desse modo, quando lemos ou produzimos algum texto, sempre recorremos a estratégias sociocognitivas.

Então, o desenvolvimento da linguagem deficitário e/ou tardio em Libras e Português, aliado às práticas educacionais que não consideram as concretas necessidades linguísticas dos surdos, contribuem para a discursivização desses sujeitos como inabilidosos leitores e escritores diante do padrão ouvinte. Assim, reconhecemos a importância do THE no sentido de trazer-

\footnotetext{
${ }^{11}$ Apenas algumas disciplinas são ministradas em Língua Portuguesa por professores nẫo fluentes em Libras, quais sejam: Educação Especial sob uma Perspectiva Inclusiva, Fundamentos Sociofilosóficos da Educação, Psicologia Educacional, Organização da Educação Brasileira.
} 
mos para o centro das discussóes a existência do surdo como sujeito histórico agindo no mundo por meio dos diversos jeitos surdos (possíveis) de ser (Perlin \& Reis, 2012).

\subsection{Segunda etapa: Redaçáo}

Após discorrermos acerca do THE, primeira etapa do vestibular de cunho eliminatório, deter-nos-emos na segunda, constituída pela elaboração de uma redação, possuindo caráter classificatório. $\mathrm{O}$ candidato deve, por conseguinte, produzir um texto argumentativo em português sendo o tema determinado pela COMPERVE. Sobre essa fase do processo seletivo, temos o seguinte relato:

A prova ter uma etapa escrita é necessário, pois temos a L2. O curso é Libras barra (/) língua portuguesa. Por exemplo, a prova tem a primeira fase em Libras, depois uma parte escrita. O surdo precisa saber sim o português, até para se autoavaliar. Como está a minha escrita? Em que eu preciso melhorar para entrar no curso? A Leitura tem sim uma grande importância. (Pérola, 2016)

No contexto do curso de LLLP, a língua portuguesa é compreendida como segunda língua para usuários de Libras, conforme orientação legal (Lei n ${ }^{\circ} 10.436 / 2002$ e Decreto $n^{\circ}$ 5.626/2005). Ao considerar o português nessa orientação, amplia-se o engendramento de um fazer pedagógico que proporcione a circulação dos saberes surdos ${ }^{12}$ nas aulas e, ainda, o papel da Libras como mediadora, tanto no acesso quanto no processo de construção do conhecimento (Silva, 2012). Vale destacarmos que, nessa etapa, se tem a constituição de uma equipe de profissionais com experiência na avaliação de textos produzidos por surdos. A respeito desse ponto, notadamente, os informantes apresentaram preocupação com o modo de correção da prova.

Sobre a etapa escrita, temos a redação, mas não sabemos se quem corrige conhece as diferenças da escrita do surdo. Se tivéssemos um vídeo em Libras e o surdo tivesse que fazer a tradução, quem fosse corrigir teria um parâmetro do que esperar. (Rubi, $6^{\circ}$ período do curso de LLLP)

De fato, fica garantido ao candidato surdo a implementação da correção flexibilizada que privilegia o conteúdo semântico e examina as influências da primeira língua na escrita. A recomendação dessa forma de lidar com o escrito do surdo encontra-se na Portaria $\mathrm{n}^{\circ} 3.284$, de 7 de novembro de 2003, que, igualmente, apresenta outras orientações para a efetivação da inclusão do surdo no Ensino Superior, como: oferta de interpretação Libras/Português (especialmente, tratando da realização e revisão de provas); o aprendizado da Língua Portuguesa na modalidade escrita, para o uso de vocabulário pertinente às disciplinas do curso em que o estudante estiver matriculado; e a oferta ao professor de conhecimentos a respeito da especificidade linguística desse sujeito.

Concernente a esse cenário de condições de acessibilidade à pessoa surda ou com deficiência em processos seletivos, estão as recomendaçóes elaboradas pelo Conselho Nacional de Direitos das Pessoas com Deficiência (CONADE), a saber: o reconhecimento da Libras nos

12 A expressão "saberes surdos" constitui-se como legado histórico pertencente à cultura das pessoas surdas. É o que caracteriza as identidades e as estratégias de sobrevivência e as formas de estabelecerem sua presença. Tratando-se do ensino de uma segunda língua, os saberes surdos confrontam - no sentido de estar em paralelo - duas línguas e suas culturas (Silva, 2012, p. 266). 
editais de concursos; a oferta do Exame Nacional para Certificação de Proficiência no Ensino da Língua Brasileira de Sinais e para Certificação de Proficiência na Tradução e Interpretação da Libras/Língua Portuguesa; a proposição de repensar os critérios avaliativos direcionando o olhar, particularmente para o conteúdo semântico (diferenciando conhecimento de desempenho linguístico); e, finalmente, o fortalecimento de que as avaliaçóes sejam corrigidas por docentes de Língua Portuguesa para surdos ou professores de Língua Portuguesa acompanhados de um intérprete de Libras (Lei $\left.{ }^{\circ} 12.319,2010\right)$.

Diante desse cenário, observamos que a UFRN, por meio do curso de Letras Libras/ LP, vem demonstrando interesse em responder às demandas apresentadas pela comunidade surda no que concerne à acessibilidade linguística para a admissão no Ensino Superior. Entretanto, interessa-nos, igualmente, o espraiamento de tais açóes para o período de estudos do universitário surdo, em concordância aos eixos que justificam a escolha de nosso objeto de pesquisa, apresentados na introdução.

\subsection{Atuaçáo dos tradutores/ intérpretes de Libras no curso de Letras Libras/ Língua Portuguesa da UFRN}

A constituição de um ambiente bilíngue para os surdos prevê a livre circulação dos saberes surdos por meio da língua de sinais e do português escrito como segunda língua. Desse modo, em momentos que ocorre a presença de professores náo fluentes em Libras, faz-se necessária a figura de um intermediador no processo comunicacional: o tradutor/intérprete de Libras (TILS). De acordo com Lacerda (2009), “quando um intérprete de língua de sinais é inserido em sala de aula, fica aberta a possibilidade de o aluno surdo receber a informação escolar na língua de sinais, através de uma pessoa competente nessa língua” (p. 34). O TILS tem, portanto, o papel de mediar as relaçóes linguísticas entre os sujeitos (surdos e ouvintes) que compóem os processos de ensino e de aprendizagem.

A respeito da presença do TILS em sala de aula, no contexto do CLLLP, temos o seguinte depoimento:

Sobre o professor ouvinte com a presença do intérprete essa tem sido a maior barreira, enquanto ele ministra sinto que há uma diferença entre o que ele fala e o que é sinalizado. O ideal é que todos os professores do curso sinalizassem. (Esmeralda, 2016)

Diante dessa informação, sublinhamos dois aspectos: o primeiro refere-se à importância da relação direta entre o universitário surdo e o professor ouvinte para que sejam minimizadas possíveis barreiras pedagógicas e comunicacionais. De acordo com Silva (2012), "a tradução compromete a qualidade do ensino, a relação entre professor e aluno e consequentemente, a apreensão do conhecimento por parte do aluno, náo basta traduzir é preciso interagir com o aluno" (p. 272). Observamos que o fato de o Letras Libras/LP ter como língua de instrução a Língua Brasileira de Sinais gera, nos calouros surdos, expectativas de que todos (alunos e professores) sejam bilíngues, porém não é isso o que acontece.

À vista disso, identificamos uma disparidade entre o que consta no Projeto Pedagógico do Curso de LLLP e o que por certo se apresenta na realidade interna das aulas. No documento 
mencionado, não encontramos evidências atinentes à garantia de que todos os professores que atuam no curso sejam fluentes em Libras e, por conseguinte, sejam capazes de ministrar suas aulas nessa modalidade visual-espacial sem a presença do intérprete de Língua de Sinais.

O segundo aspecto, ao qual nos deteremos mais minuciosamente, trata da função do TILS. Com base na afirmação de Esmeralda, em 2016, apreendemos a pertinência da competência do TILS para transmitir as explicações, as consideraçóes e as interaçóes próprias do ambiente de sala de aula da forma mais próxima da realidade discursiva. Assim, torna-se necessário possuir "conhecimentos específicos para que sua interpretação seja compatível com o grau de exigência e possibilidades dos alunos que está atendendo" (Lacerda, 2009, p. 36).

É importante que os TILS invistam em formação para melhorar a fluência. Não há um consenso nos sinais usados também. Vários TILS são de outro estado. A atuaçáo no curso de LLLP não pode ser básica. (Musgravite, 2016)

Isso significa que se faz impreterível que os TILS possuam uma formação sólida e de qualidade para que se apropriem das técnicas e das habilidades necessárias para a atuação profissional com excelência, além da necessidade da existência de uma parceria entre TILS e professores, em razão de que o simples repassar informaçóes não garante o aprendizado por parte dos alunos surdos (Masutti \& Paterno, 2011).

Podemos perceber que o intérprete atuante em sala de aula precisa incorporar em sua prática os princípios imanentes da área da tradução em colaboração com as estratégias e as propostas pedagógicas engendradas pelo professor. Daí a importância de conhecer os contornos relativos ao trabalho do TILS, que também deve contar em sua formação com conhecimentos acerca das questóes didáticas para lidar com esse contexto, como podemos observar na assertiva que segue:

Falta muito nos intérpretes. Sobre o trabalho. Parece que eles não sabem o que fazer. Apenas interpretar disciplinas. Só isso? Não sei e não quero responder. É preciso o quê? Que eles façam outras atividades, como traduçáo de textos importantes no curso, se o aluno tem dúvidas ou dificuldades na compreensão de uma palavra que eles traduzam para Libras. (Rubi, 2016)

Consideramos que o posicionamento do partícipe está alinhado tanto ao repertório de atribuiçóes quanto ao modo de concretização do trabalho dos TILS, explicitado sistematicamente na Lei que regulamenta a profissão do Tradutor/Intérprete de Libras no Brasil (Lei ${ }^{\circ}$ 12.319, 2010).

Outro aspecto interessante expresso nessa legislação tange a respeito dos valores éticos, que consideram o sujeito surdo e a sua cultura, emparelhados à precisão técnica. Não obstante, apreendemos o seguinte registro no tocante à ética do TILS: "Quando há um evento ou palestra, se negam a interpretar" (Safira, 2016).

Particularmente, o TILS desempenha um importante papel de mediação da comunicação entre sujeitos, o que demanda considerar as intencionalidades conversacionais e discursivas. Por isso, surgiu a necessidade da elaboração de um código de ética contendo orientações que circunscrevessem as especificidades da execução do serviço, de modo a contribuir para que 
o intérprete possa atuar com responsabilidade, honestidade e observância na veracidade das informaçóes.

A título de exemplo, durante o horário de trabalho, o intérprete tem a incumbência de atender às solicitações que lhes forem postas mantendo uma postura ética, moral e imparcial (Quadros, 2004). Isso posto, de fato, as diretrizes do código de ética do TILS apresentam-se como fundamentais para que o direito linguístico do surdo seja garantido e as barreiras comunicacionais, ideológicas ou de cunho pessoais sejam minimizadas.

Os participantes apontaram, também, a imprescindibilidade da criação de um espaço destinado à organização das demandas interpretativas em virtude da necessidade da realização de agendamentos do serviço e do gerenciamento de tais atendimentos:

É importante que fiquem num espaço tipo um laboratório de interpretação, mas não tem. (Safira, 2016)

Sobre as solicitaçóes para os TILS, não há um agendamento. O que fazemos é ir até a coordenaçáo do curso e pedir pra eles chamarem o intérprete. Somos atendidos apenas para demandas que ocorrem naquele momento. (Berilo Vermelho, 2016)

Sobre esse aspecto, com base nos dados construídos ao longo da pesquisa de Mestrado (Paiva, 2017), a pesquisadora propôs a criação de uma coordenação para a área de interpretação que pudesse gerenciar as demandas de tradução e interpretação de forma institucional. A centralização das atividades dos TILS tem possibilitado a ampliação da circulação dos surdos, discentes e docentes, nos mais diversos espaços acadêmicos, não mais limitando-os à acessibilidade linguística em sala de aula. A ideia ganhou força por meio da Comissão Permanente de Apoio ao Estudante com Necessidade Educacional Especial (CAENE) ${ }^{13}$, que buscou viabilizar tal proposta em parceria com a coordenação do curso de LLLP.

Após meses de estudos, visitas técnicas e reunióes, a reitoria aprovou um documento orientador voltado ao gerenciamento do serviço de tradução e de interpretação que resultou na criação do Comitê dos Tradutores e Intérpretes de Língua de Sinais e Língua Portuguesa da UFRN. A integração do trabalho dos TILS, por intermédio do comitê, representou uma conquista institucional significativa para as Pessoas Surdas na universidade.

Ademais, o status de comitê oportunizou a organização, a viabilização e o aperfeiçoamento do oferecimento desse serviço de apoio. E responde a uma necessidade do curso de Letras-Libras/LP referente à garantia de que o docente e o discente surdo sejam atendidos em Libras em todos os espaços da UFRN. Em médio prazo, também poderá contribuir para a melhoria na avaliação do curso de LLLP, realizada pelo MEC, ao empreender um movimento de construir parcerias para que se vislumbre uma universidade realmente bilíngue.

Em síntese, em uma situação bilíngue ideal, todos seriam fluentes em língua de sinais e em português, dispensando a presença do TILS em sala de aula. O que permitiria que esse profissional pudesse empenhar-se em outras atribuições de suas atividades como tradução de textos acadêmicos da língua portuguesa para a Libras, a tradução dos textos dos alunos

${ }^{13}$ Atualmente chamada de Secretaria de Inclusão e Acessibilidade (SIA). 
e o atendimento a outras demandas que assegurem o direito linguístico no âmbito em toda universidade.

De toda forma, o TILS compóe o contexto bilíngue, pois "os espaços de tradução e interpretação cumprem o papel simbólico de ser um dos locais de mais forte intermutabilidade e de contínua transformação" (Perlin \& Reis, 2012, p. 43). Isso significa que o TILS participa da mediação da produção cultural surda; entretanto, devemos desmistificar que esse profissional irá garantir a inclusão e/ou a resolução dos problemas educacionais dos surdos.

\subsection{ATUaÇÃo dos TÉCNicos QUe ATENDEM AO CURSO de LLLP}

A ausência de uma língua compartilhada em outros espaços do curso pode gerar a desestabilização do estudante surdo, reforçando o sentimento de incompletude, pois negar ouminimizar a importância da língua de sinais reforça as representaçóes da alteridade deficiente ou anormal que "resulta assim numa invenção que parece referir-se a um outro concreto, mas que hoje só tem sentido se afasta desse outro concreto - se é que ele existe - e se volta furiosa para a mesmidade" 14 (Skliar, 2003, p. 153). Sobre essa questáo, encontramos o seguinte registro:

Sobre a acessibilidade em Libras em outros espaços do curso, não há. Por exemplo, na secretaria não sabem se comunicar conosco. Apenas aquele básico "Oi, tudo bem?" Apenas isso... Além dos TILS e dos professores, os demais não sabem Libras. (Musgravite, 2016)

Desse modo, é imprescindível ao surdo ter acesso à performatividade que implica a ideia de tornar-se, não apenas em contato com o outro igual, mas também com outro diferente, pois a utilização da língua de sinais instaura-se como luta cultural. Percebe-se que, fora do contexto de sala de aula, a língua de sinais ainda permanece como coadjuvante, pois ela parece estar sendo admitida, mas o português mantém-se como a língua mais importante nos demais espaços.

Assim, a educaçáo de surdos na perspectiva bilíngue toma uma forma que transcende as questóes puramente linguísticas. Para além da língua de sinais e do português, esta educação situa-se no contexto de garantia de acesso e permanência na escola. Essa escola está sendo definida pelos próprios movimentos surdos: marca fundamental da consolidação de uma educaçấo de surdos em um país que se entende equivocadamente monolíngue. $\mathrm{O}$ confronto se faz necessário para que se constitua uma educação verdadeira: multilíngue e multicultural. Assim, no Brasil, o "bi" do bilinguismo apresenta outras dimensóes. (Quadros, 2010, p. 35)

Nesse espaço de negociação e de conflitos, entre as diferentes modalidades linguísticas, não podemos deixar de destacar que ambas integram os saberes surdos que se constituem "como legado histórico pertencente à cultura das pessoas surdas. É o que caracteriza as identidades e as estratégias de sobrevivência e formas de estabelecerem sua presença” (Silva, 2012, p. 266).

O que eu sonho para o Letras Libras, minha maior vontade é: que os professores todos sejam bilíngues, que a coordenação seja fluente em Libras, que as pessoas que atuem na secretaria também saibam Libras, ou seja, que o curso seja bilíngue. Que dentro do CCHLA tenha um departamento de Libras, assim os intérpretes atuariam em seminários, nos eventos. Que a coordenação de Libras seja por alguém que conheça em profundidade essa área. Por exemplo, a

${ }^{14}$ A mesmidade que proíbe a diferença. A diferença que torna a lei da mesmidade impossível (Skliar, 2003, p. 39). 
coordenação do curso de Letras português, por alguém de português, de espanhol por alguém de espanhol, de inglês por alguém de inglês, de Libras por alguém de Libras. Deveria ser assim. Seria muito melhor. É preciso que isso seja valorizado pela UFRN. (Aquamarine, 2016)

A pessoa surda transita entre duas culturas, a surda e a ouvinte; no entanto, sua identidade constitui-se como outro processo por ser definitivamente diferente, necessitando de recursos completamente visuais. Os ouvintes participantes dos contextos da educação bilíngue precisam incorporar a cultura surda a fim de que as concepçóes da cultura ouvinte possam ser transformadas em artefatos culturais próprios da cultura visual, característica dos surdos.

Em suma, a educaçáo bilíngue de surdos, na perspectiva dos Estudos Surdos, oportuniza que o curso de LLLP contribua para a construção da identidade surda náo mais no vazio, mas a partir do confronto com novos ambientes e espaços de possibilidades. Para tanto, é imperioso que a língua de sinais circule não apenas nas salas de aula do curso, mas também nos diversos espaços da instituição.

\section{Conclusóes}

Este artigo teve o propósito de apresentar as açóes concernentes à acessibilidade linguística da Pessoa Surda que foram implementadas pelo Curso de Letras-Libras/Língua Portuguesa (CLLLP) da Universidade Federal do Rio Grande do Norte (UFRN). No caso de surdos que ingressaram no Ensino Superior, estes percorreram uma trajetória de desafios até conseguirem chegar a esse nível de ensino. Os sentidos que os próprios sujeitos dáo a essa trajetória no curso, no que diz respeito à acessibilidade linguística, contribuíram para pensar-se e propor políticas educacionais voltadas a esse segmento, além de estabelecer estratégias institucionais de enfrentamento aos desafios que săo inúmeros e, às vezes, parecem intransponíveis.

A questão da acessibilidade linguística para surdos nas instituiçóes escolares constitui um ponto nodal para o processo de inclusão desses sujeitos na sociedade. Desse modo, ao propormos entremear as açôes voltadas a oportunizar a acessibilidade linguística dos acadêmicos surdos com os discursos desses sujeitos, tivemos a oportunidade de perscrutar a eficácia e as possíveis melhorias referentes tanto às políticas educacionais quanto às estratégias institucionais implementadas pela UFRN.

Observamos que a temática da acessibilidade náo apenas tem sido pauta permanente na instituição como tem empenhado esforços para a elaboração de ações que contemplem as singularidades dos estudantes surdos como, por exemplo: o vestibular em Libras, a atuaçáo de docentes bilíngues no curso, as aulas ministradas com a presença de TILS. Tais açôes transcendem o pensar somente na garantia de entrada desses alunos no Ensino Superior, pois buscam contemplar sua permanência, a formação de qualidade e a livre circulação linguística nos diversos espaços acadêmicos.

É válido ressaltar que a entrada dos surdos no Ensino Superior não deve restringir-se apenas ao curso de LLLP, pois ele pode ter afinidade com outras áreas do conhecimento, adentrando assim outros cursos. Dessa forma, torna-se necessário considerar as complexidades que permeiam a acessibilidade desses sujeitos que possuem vivências tão díspares e contingentes. 
Assim, para além da presença do TILS ou do professor bilíngue, deve-se considerar a importância da produção de materiais acessíveis, a formação em Libras e as discussóes sobre os Estudos Surdos para toda a comunidade acadêmica e, em especial, para o professor que atuará diretamente com esses alunos. Tais problematizaçóes são importantes para que se possa repensar políticas, açóes e estratégias juntamente à comunidade surda, ofertando a esses sujeitos a possibilidade de prosseguir com seus estudos, impulsionando-os a vislumbrar sua formação de modo contínuo e extrapolar os limites da graduação.

\section{REFERÊNCIAS}

Decreto No 5.626, de 22 de dezembro de 2005. Regulamenta a Lei no 10.436, de 24 de abril de 2002. Dispóe sobre a Língua Brasileira de Sinais - LIBRAS. http://www.planalto.gov.br/ccivil_03/_ ato2004-2006/2005/decreto/d5626.htm

Han, B-C. (2018). A expulsão do outro. Relógio d'Água Editores.

Lacerda, C. B. F. de. (1998). Um pouco da história das diferentes abordagens na educação de surdos. Caderno CEDES, 19(46), 68-80. https://doi.org/10.1590/S0101-32621998000300007

Lacerda, C. B. F. de. (2009). Intérprete de Libras em atuação na educação infantil e no ensino fundamental. Editora Mediação.

Lacerda, C. B. F. de, \& Lodi, A. C. B. (2009). A inclusão escolar bilíngue de alunos surdos: princípios, breve histórico e perspectivas. In C. B. F. de Lacerda, \& A. C. B. Lodi (Orgs.), Uma escola duas linguas: letramento em língua portuguesa e lingua de sinais nas etapas iniciais de escolarizaçâo (pp. 1132). Editora Mediação.

Lei no 10.098 , de 19 de dezembro de 2000. Estabelece normas gerais e critérios básicos para a promoção da acessibilidade das pessoas portadoras de deficiência ou com mobilidade reduzida, e dá outras providências. http://www.planalto.gov.br/ccivil_03/LEIS/L10098.htm.

Lei $\mathrm{n}^{\circ}$ 10.436, de 24 de abril de 2002. Dispóe sobre a Língua Brasileira de Sinais - LIBRAS. http://www. planalto.gov.br/ccivil_03/leis/2002/110436.htm

Lei $\mathrm{n}^{\circ} 12.319$, de $1^{\circ}$ de setembro de 2010. Regulamenta a profissão de Tradutor e Intérprete da Língua Brasileira de Sinais - LIBRAS. http://www.planalto.gov.br/ccivil_03/_Ato2007-2010/2010/Lei/ L12319.htm

Lei $\mathrm{n}^{\circ}$ 13.146, de 6 de julho de 2015. Institui a Lei Brasileira de Inclusão da Pessoa com Deficiência (Estatuto da Pessoa com Deficiência). http://www.planalto.gov.br/ccivil_03/ato2015-2018/2015/ lei/113146.htm.

Lodi, A. C. B. (2004). A leitura como espaço discursivo de construção de sentidos: oficinas com surdos [Tese de Doutorado, Pontifícia Universidade Católica de São Paulo]. Sistema de Publicação Eletrônica de Teses e Dissertaçôes - TEDE. http://www.leffa.pro.br/tela4/Textos/Textos/Teses/ana_claudia_lodi. pdf.

Masutti, M. L., \& Paterno, U. (2011). Tradução e Interpretação de LIBRAS. UFSC.

Oliveira, L. N. S., \& Silva, G. O (2016). Ingresso de Surdos no Ensino Superior: relato de experiência sobre tradução do vestibular para Libras na UFRN [Apresentação em Seminário]. VII Seminário Nacional sobre Educação e Inclusão Social de pessoas com necessidades educacionais especiais, Natal, Rio Grande do Norte, Brasil. https://ce.ufrn.br/comunicacao/noticias/vii-seminario-nacional-sobreeducacao-e-inclusao-social-de-pessoas-com-necessidades-educacionais-especiais/18224575 
Paiva, G. O. da S. (2017). Estudantes surdos no ensino superior: reflexóes sobre a inclusão no curso de letras libras/ lingua portuguesa da UFRN [Dissertação de Mestrado, Centro de Educação, Universidade Federal do Rio Grande do Norte]. Repositório Institucional UFRN. https://repositorio.ufrn.br/ jspui/handle/123456789/24434

Perlin, G., \& Reis, F. (2012). Surdos: cultura e transformação contemporânea. In G. Perlin, \& Stumpf, M. (Orgs.), Um olhar sobre nós surdos: leituras contemporâneas (pp. 29-46). Editora CVR.

Portaria $\mathrm{n}^{\circ} 3.284$, de 7 de novembro de 2003. Dispóe sobre requisitos de acessibilidade de pessoas portadoras de deficiência para instruir os processos de autorizaçáo e de reconhecimento de cursos e de credenciamento de instituiçôes. http://portal.mec.gov.br/seesp/arquivos/pdf/port3284.pdf

Quadros, R. M. (2004). O tradutor e intérprete de lingua brasileira de sinais e lingua portuguesa. MEC: SEESP.

Quadros, R. M. (2010). O 'BI' em bilinguismo na educação de surdos. In E. Fernandes (Ed.), Surdez e bilinguismo (pp. 27-37). Mediação.

Quadros, R. M. (2014). Letras Libras: ontem, hoje e sempre. Editora UFSC.

Santos, S. A., \& Francisco, C. (2018). Políticas de tradução: um tema de políticas linguísticas? Revista Fórum, 15(1), 2939-2949. https://doi.org/10.5007/1984-8412.2018v15n1p2939

Silva, S. G. de L. (2012). Pedagogia surda e ensino de língua portuguesa para surdos. In G. Perlin, \& Stumpf, M. (Orgs.), Um olhar sobre nós surdos: leituras contemporâneas (pp. 265-274). CVR.

Skliar, C. (2003). Pedagogia (improvável) da diferença e se o outro não estivesse aí?. DP\&A.

Universidade Federal do Rio Grande do Norte. (2013). Projeto Pedagógico do Curso de Licenciatura em Letras Libras/Lingua Portuguesa da UFRN. UFRN.

Recebido em: 19/02/2020

Reformulado em: 09/06/2020

Aprovado em: 17/10/2020 
PAIVA, G.O.S. \& MELO, F.R.L.V. 